\title{
Magnetic composites based on butadiene rubber and strontium ferrites
}

\begin{abstract}
The aim of the work was the study of preparation and properties of rubber magnetic composites based on butadiene rubber (Buna CB 24). Three different types of commercially used strontium ferrites, under the trade name FD8/24, UMBS8 and S90 were applied as magnetic powdery fillers. Besides the rubber and the fillers, the rubber compounds contained only ingredients that support vulcanization process. The study was focused on the preparation of rubber magnetic composites and evaluation of magnetic filler influence on their vulcanization characteristics and cross-link density. Subsequently, the physical-mechanical and magnetic properties were investigated. The results of the study revealed that the incorporation of ferrites into the rubber matrix leads to the preparation of magnetic composites with improved physical-mechanical and magnetic characteristics, which implies that ferrites provide not only suitable magnetic properties to the rubber composites, but also reinforce the rubber matrix.
\end{abstract}

Keywords: rubber, cross-link density, vulcanization, magnetic properties, rubber matrix, magnetic composites, reinforce, physical-mechanical, SEM
Volume I Issue 5 - 2017

\author{
Jan Kruzelak,' Ivan Hudec,' Rastislav \\ Dosoudil $^{2}$ \\ 'Department of Plastics, Rubber and Fibres, Slovak University of \\ Technology, Slovakia \\ ${ }^{2}$ Department of Electromagnetic Theory, Slovak University of \\ Technology, Slovakia
}

\begin{abstract}
Correspondence: Jan Kruzelak, Department of Plastics, Rubber and Fibres, Faculty of Chemical and Food Technology, Slovak University of Technology, Radlinskeho 9, 812 37 Bratislava, Slovakia, Email jan.kruzelak@stuba.sk
\end{abstract}

Received: September 28, 2017 | Published: October 23, 2017

\section{Introduction}

Rubber magnetic composites are a group of smart materials consisting of ferromagnetic fillers incorporated in soft rubber matrix. ${ }^{1-3}$ The final properties of composites are strongly dependent on characteristics of polymer matrix especially. However, by applying of magnetic materials into rubber compounds by processing technologies generally used in rubber industry, new properties and technological abilities can be provided. The advantage of such type of materials is that their properties can be modified for the requirements of specific applications. Because of their elasticity and easy mouldability there are suitable for additive devices, where elasticity and flexibility are additional and important parameters. Rubber composites with magnetic fillers are able to sensitively respond to vibrations and absorb oscillations of various wavelengths. They can also change magnetic and mechanical properties at different forms of strain. Moreover, they have very good magnetic properties. Rubber magnets can absorb shock and sound, so they can be applied in-dc motors, motor parts, memo holders, intelligent tyres, in microwave and radar technology, also in other technological applications..$^{4-8}$

Metal ferrites with general formula $\mathrm{MFe}_{12} \mathrm{O}_{19}(\mathrm{M}$ is divalent cation such as $\mathrm{Ba}, \mathrm{Sr}$, ect.) belong to the widely used magnetic materials. They have domain structure which terminates over the Currie temperature. High values of magneto-crystalline anisotropy and saturation magnetization allow wide application of these materials as permanent magnets. Ferrites have wide hysteresis loop and value of Coercivity $H>2.5 \mathrm{kA} / \mathrm{m}$. They also express high value of remanent magnetic induction $B_{r}$ and high value of maximum energy product $(B H)_{\max }$. They may occur in several crystallographic modifications, but in term of possible applications, ferrites with hexagonal structure express the biggest interest. ${ }^{9,10}$ As the magnetic powdery fillers, $\mathrm{Ba}$ and $\mathrm{Sr}$ ferrites are very often used. Ferrite permanent magnets of general formula $\mathrm{SrFe}_{12} \mathrm{O}_{19}$ or $\mathrm{BaFe}_{12} \mathrm{O}_{19}$ contain approximately $80 \%$ of iron oxide and $20 \%$ of strontium or barium. They have good chemical stability, low specific weight and suitable magnetic characteristics.
Low price and chemical resistance are next benefits of these magnetic materials which have become very important materials as media for magnetic and magnetic-optical recording, as components for reproducers, engines and generators in automobile industry. ${ }^{11-14}$

\section{Experimental}

\section{Materials}

Butadiene rubber (BR, Buna CB 24, Lanxess, Germany) was chosen as soft elastomeric matrix for the preparation of rubber magnetic composites. Three types of strontium ferrites were applied as magnetic powdery fillers. Anisotropic strontium ferrite, type FD 8/24, was provided by Magnety, a.s. (Světla Hora u Bruntalu, Czech Republic). Strontium ferrite, commercially marked as UMBS8, was provided by Unimagnet Industry Co., Ltd. (Yhuji City, China). Strontium ferrite, under the trade name S90, was provided by Tridelta GmbH (Hermsdorf, Germany). The amount of ferrite in rubber compounds changed from 0 to $100 \mathrm{phr}$. Besides the rubber and magnetic fillers, the rubber compounds contained components of vulcanization system (sulphur-1.3 phr, N-cyclohexyl2-benzothiazolesulfenamide-1.5 phr, ZnO-3 phr, stearin-2phr). IPPD (N-isopropyl-N"-phenyl-p-phenylenediamine) was introduced into rubber compounds as an antioxidant.

\section{Methods}

Evaluation of structural characteristics of strontium ferrites: The specific surface area and total porosity of strontium ferrites were determined by applying the method of mercury porosimetry. The measurement was carried out by using Porosimeter 1500 (Carlo Erba, Milan, Italy). Maximum press of mercury $150 \mathrm{MPa}$ enables to determine pores up to the size of $5 \mathrm{~nm}$. Particle size distribution of tested fillers was investigated by using Cilas 1064L appliance (Cilas, France). Fine particles are measured by scanning of scattering reflection, which is formed by examined sample. The time of detection is 20 seconds in liquid state. Measuring is performed in the range of attenuation of 
laser beam from 5 to $28 \%$. The microstructure of the applied ferrites was observed using the scanning electron microscope Tesla BS 300 with digitizing unit Tescan equipped with Wintip software. The surface of ferrite powders was coated with a thin layer of gold and placed into the scanning electron microscopy (SEM). Density of ferrites was provided by the manufacturers.

Preparation of rubber compounds: The rubber compounds were prepared in the laboratory mixer Brabender in two mixing steps. In the first step, the rubber and the fillers were compounded (9min, $\left.90^{\circ} \mathrm{C}\right)$, in the second step $\left(4 \mathrm{~min}, 90^{\circ} \mathrm{C}\right)$, the vulcanization system was introduced. Subsequently the rubber blends were homogenized in two roll calander. The vulcanization characteristics of rubber compounds were investigated from the corresponding vulcanization isotherms measured by Rheometer Monsanto R100 at $150^{\circ} \mathrm{C}$. The vulcanization process was performed at $150^{\circ} \mathrm{C}$ for the optimum vulcanization time under a pressure of $15 \mathrm{MPa}$ by using the hydraulic press Fontijne. Finally, thin sheets (width $15 \times 15 \mathrm{~cm}$, thickness $2 \mathrm{~mm}$ ) of vulcanized rubber compounds were obtained.

Determination of cross-link density of composites: The cross-link density $v$ was determined based on equilibrium swelling of samples in xylene. First, the samples were swelled in xylene until the equilibrium swelling was reached. The cross-link density was calculated based upon equilibrium swelling degree by applying the Krause modified Flory-Rehner equation (1) for filled vulcanizates: ${ }^{15}$

$$
v=-\frac{V_{r 0}}{V_{S}} \frac{\ln \left(1-V_{r}\right)+V_{r}+\chi V_{r}^{2}}{V_{r}^{1 / 3} V_{r 0}^{2 / 3}-0.5 V_{r}}
$$

$v$ - Cross-link density $\left(\mathrm{mol} / \mathrm{cm}^{3}\right)$

$\mathrm{V}_{\mathrm{r} 0}$-Volume fraction of rubber in equilibrium swelling sample of vulcanizate in absence of fillers

$\mathrm{V}_{\mathrm{r}}$ - Volume fraction of rubber in equilibrium swelling sample of filled vulcanizate

$$
\mathrm{V}_{\mathrm{S}} \text { - Molar volume of solvent (for xylene }=123.45 \mathrm{~cm}^{3} / \mathrm{mol} \text { ) }
$$

$\chi$ - Huggins interaction parameter (for measuring conditions $\chi=0.39$ )

Evaluation of physical-mechanical properties of composites: The tensile properties of tested composites were evaluated by using Zwick Roell/Z 2.5 appliance at a cross-head speed of $500 \mathrm{~mm} / \mathrm{min}$ and laboratory temperature in accordance with the valid technical standards, on the double side dumbbell-shaped test specimens (width $6.4 \mathrm{~mm}$, length $8 \mathrm{~cm}$, thickness $2 \mathrm{~mm}$ ).

Determination of magnetic characteristics of ferrites and composites: Magnetic characteristics of tested ferrites and also prepared composites were determined at a room temperature and maximum coercivity of $H_{m}=750 \mathrm{kA} / \mathrm{m}$. For this purpose, magnetometer TVM-1 was used. The basic principle of measurement is induction method of scanning of scattering magnetic flux induced by magnetic vibrating sample. Magnetic field is generated by means of two cores of Weiss electromagnet at a minimum distance of poles adapters $7.5 \mathrm{~mm}$. The specimens of composites were of prism shape $(8 \mathrm{x} 4 \mathrm{x} 4 \mathrm{~mm})$.

There was experimentally determined the coercivity $H_{c}$, the maximum magnetic flux $\Phi_{m}$ and remanent magnetic flux $\Phi_{r}$ for all composites. The maximum magnetic polarization $J_{m}$ and the remanent magnetic polarization $J$ were calculated based on experimentally determined $\Phi_{m}$ and $\Phi_{r}$ values using equations (2) and (3):

$$
\begin{aligned}
& J_{m}=\frac{\Phi_{m}}{S} \cdot D \\
& J_{r}=\frac{\Phi_{r}}{S} \cdot D
\end{aligned}
$$

S - surface area of the sample

D - constant of the used apparatus TVM-1 $(D=16.4)$

The magnetic saturation $B_{s}$ and the remanent magnetic induction $B_{r}$ were calculated utilizing equations (4) and (5):

$$
\begin{aligned}
& B_{s}=\mu_{0} \cdot H_{m}+J_{m} \\
& B_{r}=\mu_{0} \cdot H+J_{r} \Rightarrow B_{r}=J_{r}
\end{aligned}
$$

$\mu_{o}$-vacuum permeability

$H_{m}$-maximum intensity of magnetic field $\left(H_{m}=750 \mathrm{kA} / \mathrm{m}\right)$

$H$-intensity of magnetic field $(H=0 \mathrm{kA} / \mathrm{m})$

\section{Results and discussion}

\section{Characteristics of ferrite fillers}

For detailed characterization of applied strontium ferrites, structural, magnetic and other physical characteristics were determined. Structural characteristics (shape and size of ferrite particles) were evaluated by scanning electron microscopy. SEM images of ferrites powders at different magnifications are illustrated in Figures 1-3. From them it is shown that magnetic fillers form aggregates of various sizes and shapes. The structural characteristics of ferrites S90 and UMBS seem to be very similar. As possible to observe from Figures $1 \&$ Figure 2, the particles of those ferrites are very similar in their size and shape. The particle size distribution revealed that the size of ferrites S90 and UMBS ranged from 1 to $40 \mu \mathrm{m}$, while the highest amount of particles moved around $5-10 \mu \mathrm{m}$. From Figure 3 it becomes evident that the size of ferrite FD8/24 seems to be larger, ranging from 1 to $80 \mu \mathrm{m}$, which can be probably caused by higher agglomeration of filler particles.

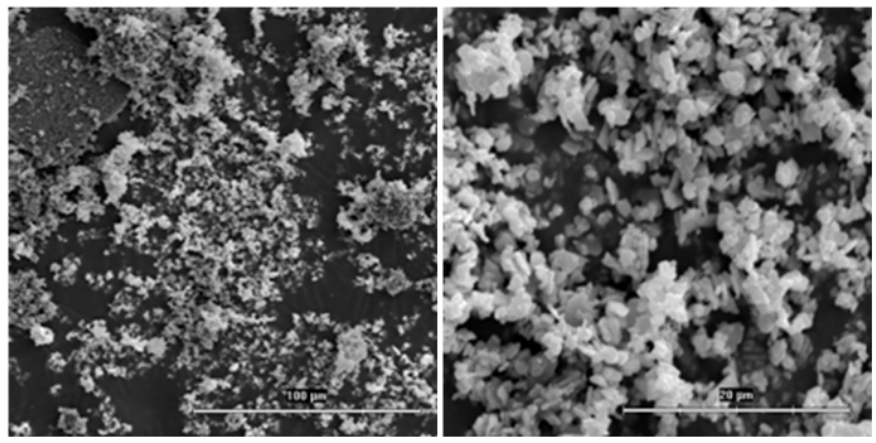

Figure I SEM images of strontium ferrite S90.

The detailed specifications of magnetic fillers are presented in Table 1. As possible to see, the largest specific surface area exhibits ferrite FD8/24, the smallest one ferrite UMBS8. Its value is more than $1 \mathrm{~m}^{2} / \mathrm{g}$ smaller than that of FD8/24. By contrast ferrite FD8/24 shows 
the lowest total porosity, at about $10 \%$ lower in comparison with rest two types of ferrite powders. The coercitive intensity of magnetic field (coercivity) $H_{c}$, is the lowest for the type FD8/24. The coercivities of ferrites S90 and UMBS are almost twofold higher in comparison with FD8/24. The values of remanent magnetic induction of all type ferrites are comparable, although the highest $B_{r}$ was determined in the case of FD8/24.

Table I Characteristics of strontium ferrites

\begin{tabular}{|c|c|c|c|}
\hline Characteristics & $\mathbf{S 9 0}$ & UMBS8 & FD8/24 \\
\hline Density $\left(\mathrm{g} / \mathrm{cm}^{3}\right)$ & 4.99 & 4.98 & 4.73 \\
\hline Particles Size $(\mu \mathrm{m})$ & Jan-40 & Jan-40 & Jan-80 \\
\hline Specific Surface Area $\left(\mathrm{m}^{2} / \mathrm{g}\right)$ & 3.23 & 2.92 & 4.06 \\
\hline Total porosity (\%) & 64.87 & 65.34 & 55.62 \\
\hline Coercivity $\mathrm{H}_{\mathrm{c}}(\mathrm{kA} / \mathrm{m})$ & 220 & 287 & 117 \\
\hline Magnetic Saturation $B_{s}(T)$ & 1.18 & 1.21 & 1.26 \\
\hline $\begin{array}{l}\text { Remanent Magnetic Induction } \\
B_{r}(T)\end{array}$ & 0.145 & 0.162 & 0.17 \\
\hline
\end{tabular}
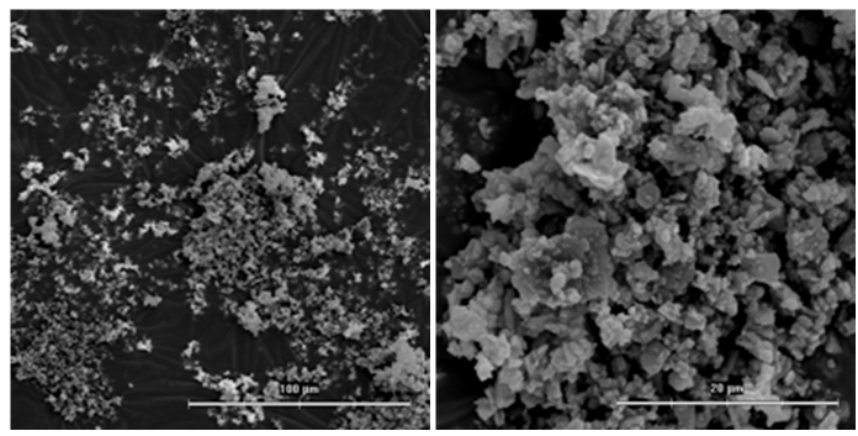

Figure 2 SEM images of strontium ferrite UMBS8.
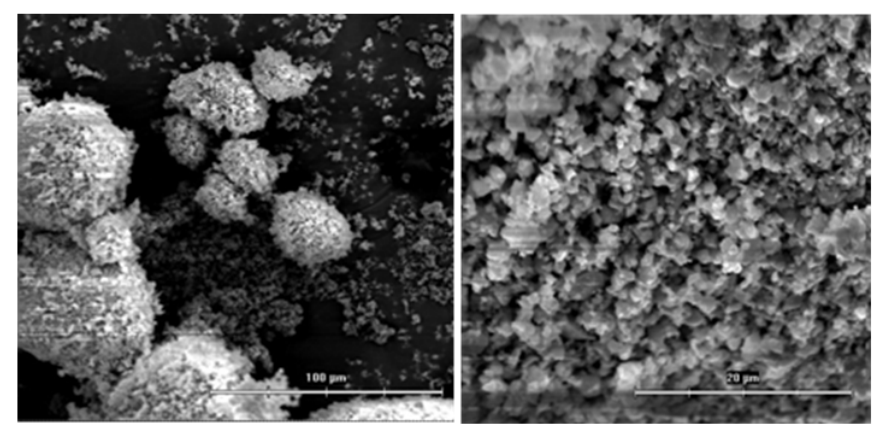

Figure 3 SEM images of strontium ferrite FD8/24.

\section{Influence of ferrites on vulcanization process of rubber compounds}

The influence of ferrites on vulcanization process of rubber compounds was considered based on the determination of vulcanization characteristics, the optimum vulcanization time $t_{c 90}$, the scorch time $t_{s l}$ and the difference between the maximum and minimum torque $\mathrm{dM}$. The values of these characteristics were determined from the corresponding vulcanization isotherms measured at $150^{\circ} \mathrm{C}$.
From Figure 4 it is obvious that the scorch time of rubber compounds filled with ferrite UMBS8 first slightly increased when $20 \mathrm{phr}$ of filler was added into the rubber compound. With next increasing of ferrite content the scorch time showed a decreasing trend. The scorch time of rubber compounds filled with fillers S90 and FD8/24 was lower in comparison with the scorch time of the reference unfilled sample in all ferrite concentration range. The shortest scorch time were found to have rubber compounds filled with filler S90. The scorch time of the sample with $20 \mathrm{phr}$ of S90 decreased in about 6 min in comparison with the reference, but with next increasing of ferrite content, the values of scorch time fluctuated in low range almost independently on the amount of magnetic filler.

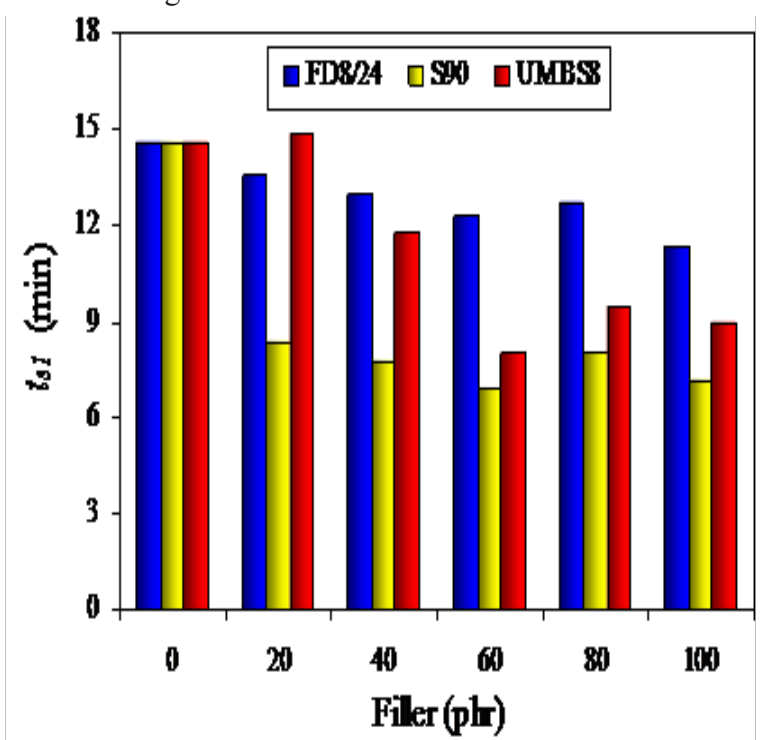

Figure 4 Influence of ferrites content on scorch time $t_{s 1}$ of rubber compounds.

As seen in Figure 5, the presence of magnetic fillers in rubber compounds leads also to the decrease of the optimum vulcanization time. The rubber compounds filled with ferrite S90 required the shortest time essential for their vulcanization process. In comparison with the unfilled sample, the addition of magnetic filler S90 caused the reduction of the optimum vulcanization time from about 28 to approximately 11 minutes (for the sample with $100 \mathrm{phr}$ of ferrite). Taking into consideration that rubber compounds differed in ferrites loading only, it is supposed that ferrites tend to accelerate sulphur vulcanization process. Ferrites are complex substances consisting of iron oxide and oxides of other metals, depending on the type of ferrite. The presence of these oxides in the rubber matrix might have a similar effect on vulcanization process as zinc oxide that acts as activator of sulfur vulcanization. Thus the total acceleration of vulcanization process of ferrites filled rubber compounds might be supported. From graphical dependence of torque difference $\mathrm{dM}$ on ferrites content (Figure 6) it is possible to observe the extension of dM values with increasing amount of all tested strontium ferrites. The type of applied ferrite has almost no influence on the torque difference.

\section{Influence of ferrites on cross-link density of composi- tes}

The cross-link density is very important characteristic of all vulcanized rubber systems. Not only the original properties, but also their changes within time are dependent on the cross-link density. The cross-link density $v$ of prepared composites was determined based on equilibrium swelling of samples in xylene by applying the Flory- 
Rehner equation (1). The calculated values of $v$ for all composites are presented in Figure 7.

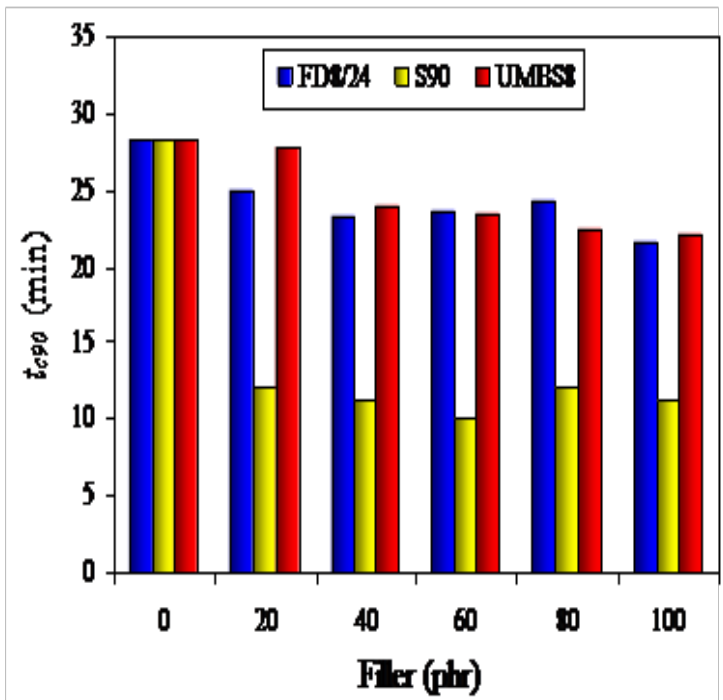

Figure 5 Influence of ferrites content on optimum vulcanization time $t_{c 90}$ of rubber compounds.

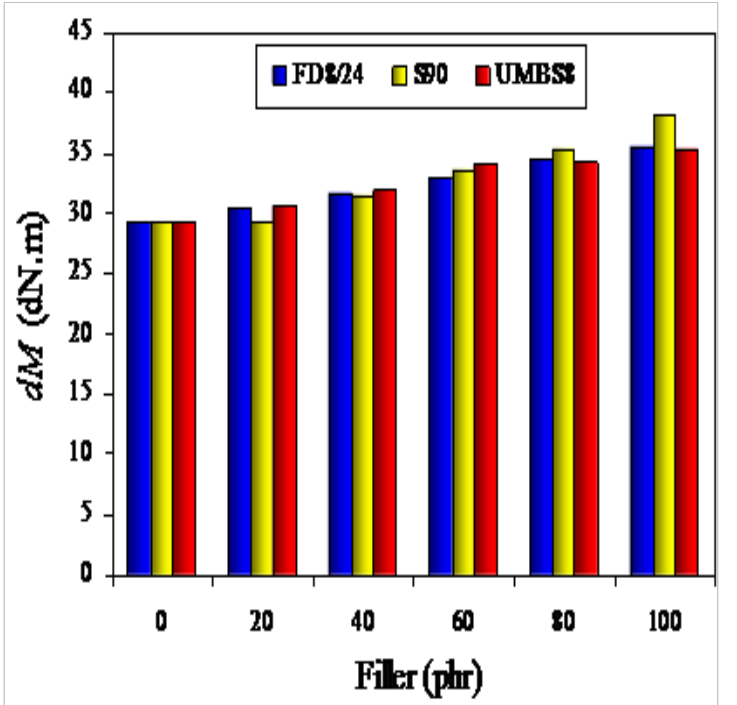

Figure 6 Influence of ferrites content on torque difference dM of rubber compounds.

The highest cross-link density showed the reference unfilled sample. The cross-link densities of all ferrites filled composites were found to be lower when compared to the reference, but almost independent on the amount of magnetic fillers. A slight decrease of cross-link density with increasing content of ferrite was recorded only in the case of composites filled with filler UMBS8. The decline of cross-link density of the composite with maximum UMBS8 content did not exceed $20 \%$ in comparison with the corresponding value $v$ of the reference. Composites filled with ferrite UMBS8 exhibited the highest cross-link density, although the differences in cross-link density in dependence on the type of magnetic filler were not very significant. The possible explanation of the decrease of cross-link density by incorporation of ferrite can be the fact that ferrite particles could act as a steric hindrance against forming of cross-links between rubber chains segments, thus contributing the decrease of cross-link density.
The lowest degree of cross-linking of composites filled with ferrite FD8/24 might be then caused by higher particles size of that filler. The similar results were also obtained in our previous work, ${ }^{16}$ although other research papers did not confirm this presumption. ${ }^{17,18}$ Therefore the type of filler and the type of rubber matrix must be also considered and the contribution of magnetic fillers on cross-link density of rubber magnets should be the subject of further investigation.

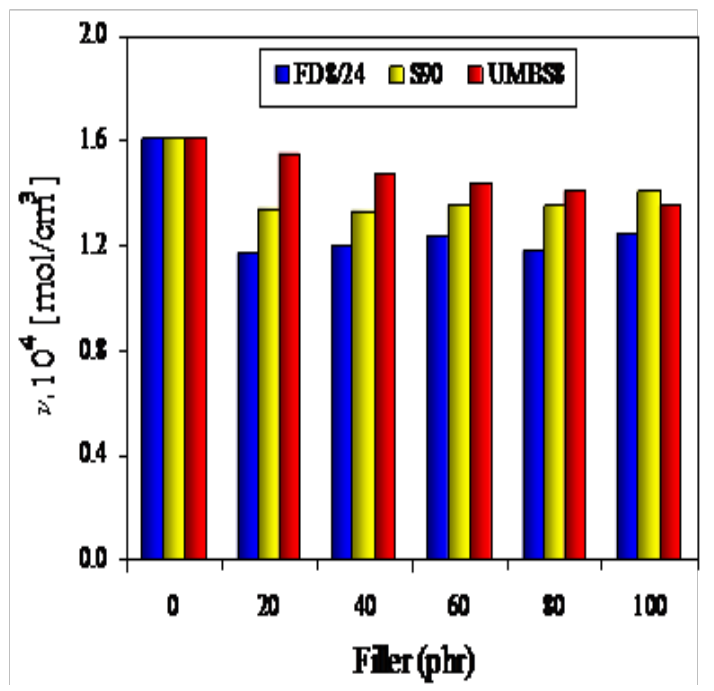

Figure 7 Influence of ferrites content on cross-link density $v$ of composites.

\section{Influence of ferrites on physical-mechanical properties of composites}

The study revealed that application of ferrites into rubber matrix leads to the improvement of physical-mechanical properties of composite materials (Figures 8-10). Composites filled with S90 exhibited the highest tensile strength in all ferrite concentration scale. The tensile strength of the maximally filled composite was almost twofold higher when compared to the reference. The tensile strength of composites filled with the rest two types of ferrites was found to be lower, but it was also positively influenced by doping content of both fillers (Figure 8). The lowest tensile strength of composites filled with ferrite FD8/24 can be attributed to the highest particle size of that ferrite. In generally, the lower is the particle size, the better interaction between the rubber and the filler on the phase interface is achieved, leading to the higher reinforcing effect of the applied filler. ${ }^{19}$ Therefore, composites filler with S90 and UMBS exhibited higher tensile strength when compared with equivalent composites filled with FD8/24. The elongation at break first rapidly increased when 20phr of filler S90 was added into the rubber matrix, but with the next incorporation of magnetic filler, the values of elongation at break remained nearly unchanged. The composites filled with this type of filler showed the highest elongation at break in all ferrite concentration range (Figure 9). The increase of elongation at break with increasing content of applied fillers can be attributed the decrease of cross-link density of composites (Figure 7). The higher is the crosslink density, the more restricted is rubber chains mobility, leading to the lower elongation at break. From Figure 10 it becomes evident that the values of modulus M100 were not possible to be measured for the reference sample and most composites as they were ruptured at the deformation less than $100 \%$. In the case of composites filled with filler FD8/24, the modulus M100 was determined only in case of the composite with maximum ferrite content. 




Figure 8 Influence of ferrites content on tensile strength of composites.

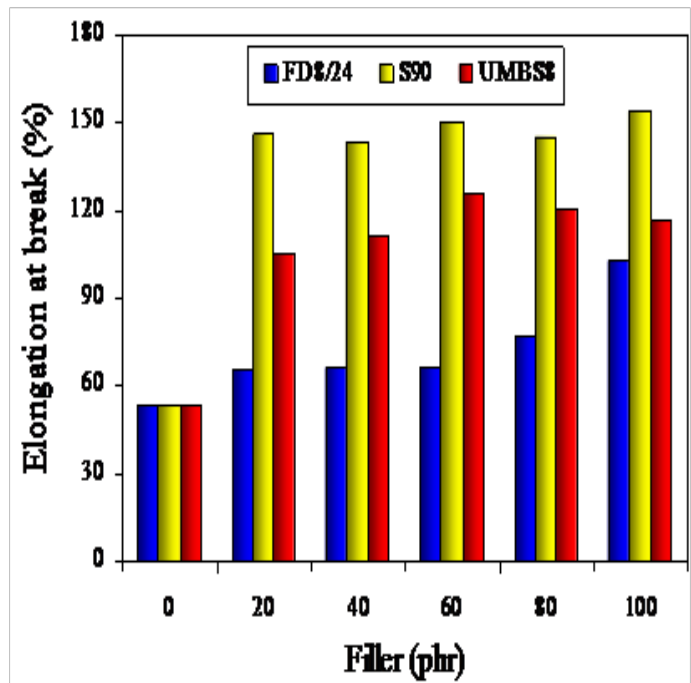

Figure 9 Influence of ferrites content on elongation at break of composites.

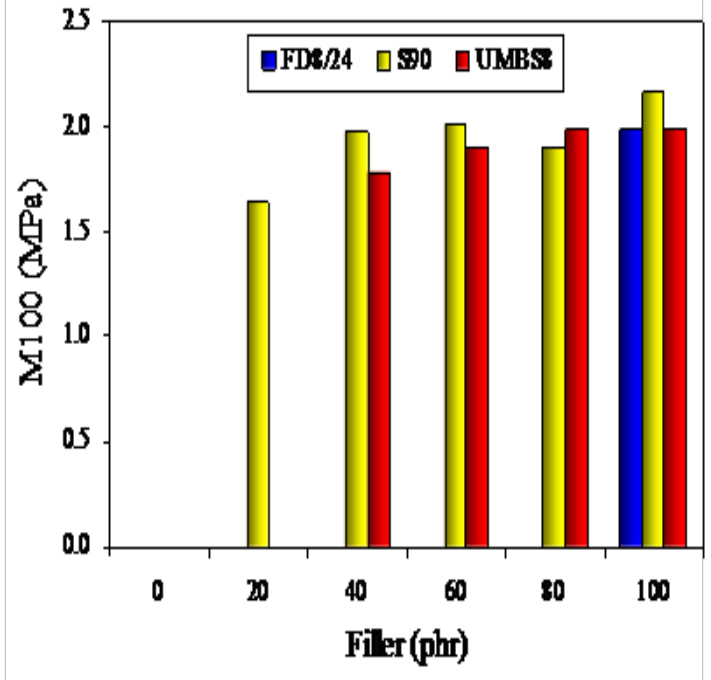

Figure 10 Influence of ferrites content on modulus MI00 of composites.
Based upon the achieved results it can be stated that ferrites applied in butadiene rubber matrix behave as reinforcing fillers, as the improvement of physical-mechanical properties by incorporation of ferrite powders was observed. As ferrite fillers have no chemical functional groups able to react with the macromolecules of the rubber matrix to form chemical couplings, it is estimated that there are formed some physical interactions between the rubber matrix and the particles of ferrite, which subsequently leads to the improvement of compatibility and adhesion on the phase interface filler-rubber. In generally, good adhesion and interactions between the rubber and the filler on the interfacial layer are the basic principle of rubber compounds reinforcement. Although, the degree of reinforcement of rubber compounds filled with ferrites is not as significant as in comparison with traditional fillers used in rubber technologies (e.g. carbon black), the achieved results revealed that this is a very promising aspect relating to the preparation of rubber composites with incorporated magnetic fillers, especially ferrites.

\section{Influence of ferrites on magnetic characteristics of composites}

The dependences of magnetic induction $B$ on intensity of magnetic field $H$ are called magnetizing curves, which provide complete information about technical properties of magnetic substances. Figure 11 illustrates the dependence of magnetic induction $B$ in the material on intensity of external magnetic field $\mathrm{H}$, when the sample is cyclically magnetized in the presence of external magnetic field from the point a to the point $d$ and back to the point a. Curve 1 corresponds to the primary magnetization of the sample from the point 0 to the point of magnetic saturation $B_{s}$. In the point a the material is completely magnetized. When the intensity of external magnetic field decreases, the magnetic induction in the sample also decreases, following the curve 2 . This points out to the irreversibility of magnetizing processes in ferromagnetic materials. When an external magnetic field vanishes, the material exhibits the remanent magnetic magnetization $B$. This means that the sample is magnetized without the presence of the external magnetic field. If the intensity of magnetic field is changed to the opposite direction, external magnetic field intensity increases, while the magnetic induction in the sample decreases. In the point corresponding to coercive intensity of magnetic field $H_{c}$ (or shortly coercivity), the magnetic induction vanishes and the material becomes demagnetized. The next increasing intensity of magnetic field leads to the increase of magnetic induction in the sample to the point of saturation $\mathrm{d}$, but in the opposite direction. If the intensity of external magnetic field is changed in the point $d$ again, the magnetic induction in the sample grows according to the curve 3 to the initial saturation $B_{s}$ in the point a. Thus one magnetizing cycle is finished. This phenomenon is called magnetic hysteresis and curve 2-3 is indicated as hysteresis loop.

The remanent magnetic induction and the coercivity are the most important parameters of all permanents magnets. Magnetic hard materials, as also ferrites, usually exhibits high values of both magnetic characteristics. Therefore, the incorporation of ferrites into rubber matrix should also impart magnetic characteristics to the rubber composites as well. The values of magnetic saturation $B$, remanent magnetic induction $B_{r}$ and coercivity $H_{c}$ for all prepared composites are graphically illustrated in Figures 12-14.

As seen in Figure 12, the magnetic saturation of prepared composites was slightly improved in dependence on fillers content, 
but the type of ferrite has almost no influence on the values of observed characteristics. From Figure 13 it becomes clearly evident that the remanent magnetic induction of tested materials was found to be strongly dependent on the amount of applied strontium ferrites. In the case of all type composites, there was recorded nearly $500 \%$ increase of $B$ by increasing of ferrites content from 20 to $100 \mathrm{phr}$. The highest values of remanent magnetic induction seem to be achieved by applying of ferrite FD8/24, the lowest $B_{r}$ values by using ferrite S90. The obtained results for the remanent magnetic induction of composites correspond with the results of $B_{r}$ for examined magnetic fillers. The highest $B_{r}$ showed ferrite FD8/24, the lowest one exhibited ferrite S90 (Table 1).

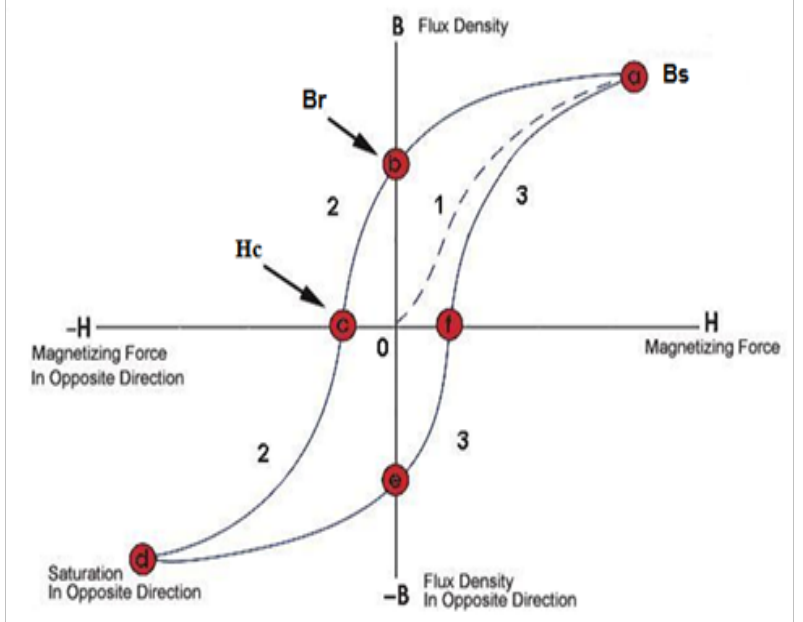

Figure I I Hysteresis loop of ferromagnetic materials.

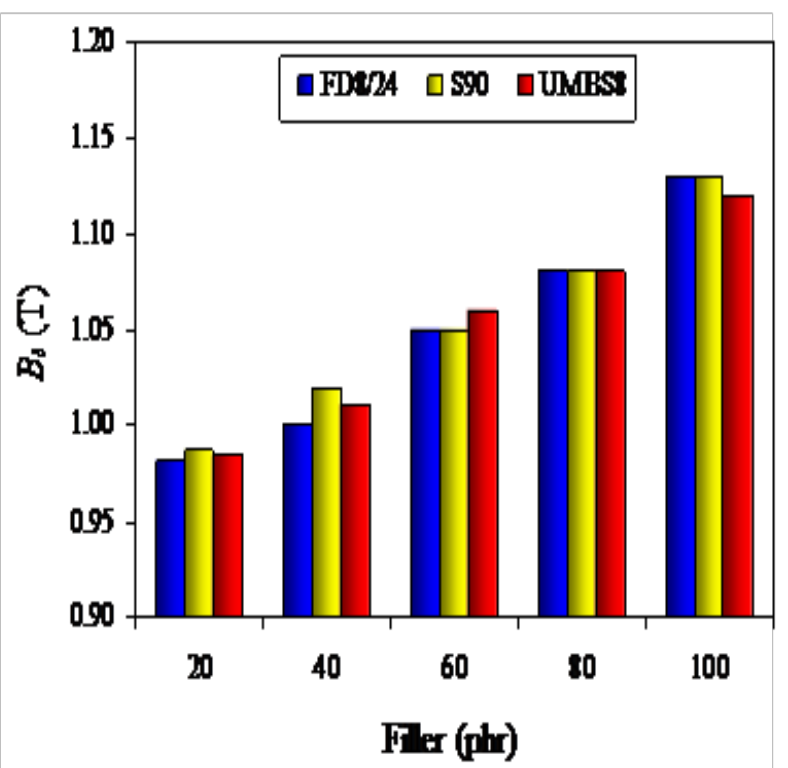

Figure 12 Influence of ferrites content on magnetic saturation $B_{s}$ of composites.

By contrast, the coercivity of composites seems not to be influenced by the magnetic fillers content, although there were spotted big differences in coercivity in dependence on the type of applied ferrite (Figure 14). The highest coercivity exhibited composites filled with ferrite UMBS8. The values of $H_{c}$ of these materials were at about $100 \mathrm{kA} / \mathrm{m}$ higher in comparison the $H_{c}$ of composites filled with ferrite $\mathrm{S} 90$ and more than twofold higher in comparison with the equivalent coercivity of composites filled with ferrite FD8/24. These results also correspond with the data mentioned in Table 1, indicating that the highest coercivity possesses ferrite UMBS8 while the lowest one the type FD8/24. This means that rubber magnetic composites filled with ferrite UMBS8 exhibit the highest resistance against demagnetization. The obtained results showed that magnetic characteristics of rubber magnetic composites are strongly dependent on the magnetic characteristics and the content of applied ferrites.

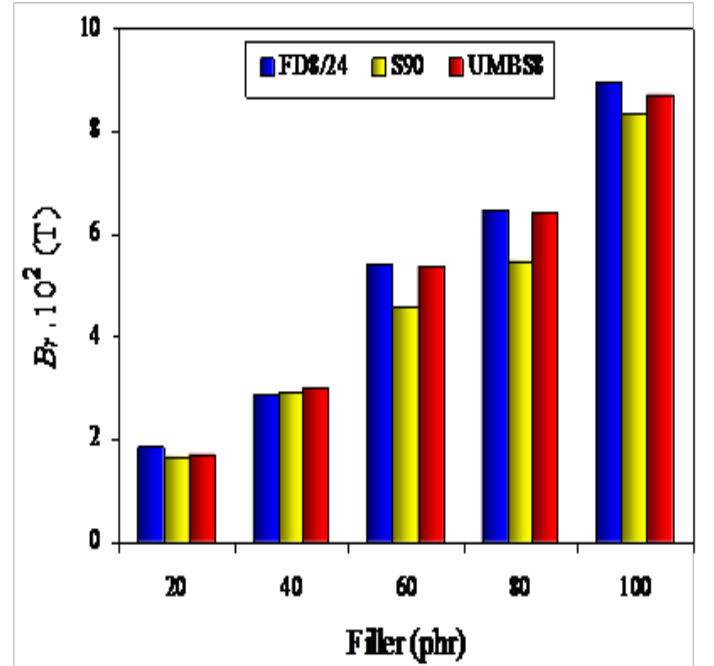

Figure 13 Influence of ferrites content on remanent magnetic saturation $B_{r}$ of composites.

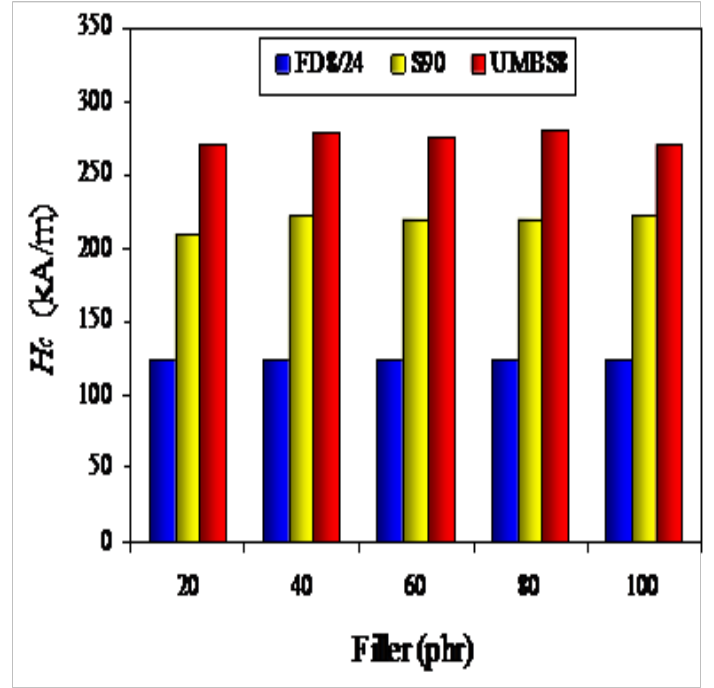

Figure 14 Influence of ferrites content on coercivity $\mathrm{H}_{c}$ of composites.

\section{Conclusion}

In this work rubber magnetic composites were prepared by incorporation of strontium ferrites into the rubber compounds based on BR. The study was focused on the preparation of composites and evaluation of magnetic fillers influence on their cross-linking and properties.

The results revealed that the incorporation of ferrite fillers into the rubber matrix leads to the acceleration of cross-linking process of rubber compounds, imparts magnetic properties and modifies physical-mechanical properties of prepared composites considerably. The remanent magnetic induction of tested composite system is 
strongly dependent on the content of magnetic fillers, while the coercivity is influenced mainly by the type of strontium ferrite. The physical-mechanical properties of rubber magnetic composites are dependent on the characteristics of rubber matrix especially, but also on the content of applied ferrites and interfacial conditions between the components. The observed properties were improved by addition of ferrites, which point out that there is good adhesion between the rubber matrix and the particles of ferrite. Relating to the tested rubber systems with incorporated magnetic fillers, the best compromise between the appropriate mechanical and magnetic properties seems to be achieved by using strontium ferrite $\mathrm{S} 90$.

\section{Ackowledgements}

This work was supported by the Slovak Research and Development Agency under the contract No. APVV-16-0136.

\section{Conflicts of interest}

The author declares no conflict of interest.

\section{References}

1. Yadhu K, Shine Ch, Nazeeha U, et al. Processability, mechanical and magnetic studies on natural rubber-ferrite composites. Int J Chem Stud. 2015;3(1):15-22.

2. Bellucci FS, de Almeida FCL, Nobre MAL, et al. Magnetic properties of vulcanized natural rubber nanocomposites as a function of the concentration, size and shape of the magnetic fillers. Compos Part B. 2016;85:196-206

3. Jung HS, Kwon SH, Choi HJ, et al. Magnetic carbonyl iron/natural rubber composite elastomer and its magnetorheology. Compos Struct. 2016;136:106-112.

4. Gutierrez J, Martins P, Goncalves R, et al. Synthesis, physical and magnetic properties of $\mathrm{BaFe}_{12} \mathrm{O}_{19} / \mathrm{P}(\mathrm{VDF}-\mathrm{TrFE})$ multifunctional composites. Eur Polym J. 2015;69:224-231.

5. Pattanayak R, Muduli R, Panda RK, et al. Investigating the effect of multiple grain-grain interfaces on electric and magnetic properties of $\left[50 \mathrm{wt} \% \mathrm{BaFe}_{12} \mathrm{O}_{19}-50 \mathrm{wt} \% \mathrm{Na}_{05} \mathrm{Bi}_{05} \mathrm{TiO}_{3}\right]$ composite system. Physica B. 2016;485:67-77.

6. El Nashar DE, Ahmed NM, Agami WR. The effect of new ferrite/kaolin pigment on the properties of acrylonitile-butadiene rubber composites. Mater Design. 2013;52:108-117.
7. Kruzelak J, Usakova M, Dosoudil R, et al. Microstructure and performance of natural rubber based magnetic composites. Polym Plast Technol Eng. 2014;53(11):1095-1104.

8. Das S, Nayak GC, Sahu SK, et al. Microwave absorption properties of double-layer composites using $\mathrm{CoZn} / \mathrm{NiZn} / \mathrm{MnZn}$-ferrite and titanium dioxide. J Magn Magn Mater. 2015;377:111-116.

9. Mahmoud KH, Makled MH. Infrared spectroscopy and thermal stability studies of natural rubber-barium ferrite composites. Adv Chem Eng Sci. 2012;2(3):350-358.

10. Milke EC, Rei M, de Souze JP, et al. Powder injection molded strontium-ferrite magnets. Int J Powder Metall. 2001;37(5):47-51.

11. Lechevallier L, LeBreton JM. Substitution effects in M-type hexaferrite powders investigated by Mössbauer spectrometry. J Magn Magn Mater. 2005;290-291:1237-1239.

12. Li J, Zhang HF, Shao GQ, et al. Synthesis and properties of new multifunctional hexaferrite powders. Procedia Eng. 2015;102:1885-1889.

13. Wang YF, Li QL, Zhang CR, et al. Preparation and magnetic properties of different morphology nano- $\mathrm{SrFe}_{12} \mathrm{O}_{19}$ particles prepared by sol-gel method. J Alloys Compd. 2009;467(1-2):284-287.

14. Xie T, Xu L, Liu Ch, et al. Synthesis and adsorption properties of high specific area strontium ferrite form Industrial Strontium Residue. Vacuum. 2013;93:71-78.

15. Kraus G. Swelling of filler-reinforced vulcanizates. J Appl Polym Sci. $1963 ; 7(3): 861-871$.

16. Kruzelak J, Dosoudil R, Sykora R, et al. Rubber composites with incorporated magnetic filler. Polimery. 2014;11-12:819-824.

17. Kruzelak J, Sykora R, Dosoudil R, et al. Magnetic composites prepared by incorporation of strontium ferrite into polar and non-polar rubber matrices. Polym Compos. 2015;38(11):2480-2487.

18. Kruzelak J, Sykora R, Dosoudil R, et al. Rubber composites based on polar elastomers with incorporated modified and unmodified magnetic filler. Adv Mater Sci Eng Article. 2016;ID:7242891. 10 p.

19. Kysela G, Hudec I, Alexy P. Manufacturing and processing of rubber. Bratislava. 1st ed. Bratislava, Slovakia: Slovak University of Technology Press; 2010. 